\section{Uso do solo urbano e alterações na rede de drenagem da bacia hidrográfica do Lajeado Passo dos Índios, Chapecó-SC}

\begin{abstract}
Resumo: O presente trabalho busca avaliar o grau das alterações indiretas vinculadas ao uso do solo urbano e diretas, sobretudo na canalização dos rios da Bacia Hidrográfica do Lajeado Passo dos Índios (BHLPI), principal drenagem do perímetro urbano de Chapecó, mesorregião Oeste Catarinense. Para tanto, se pautou na revisão de manchetes de jornais, nos mapeamentos do uso do solo (1984-2011) e das obras de canalização em ambiente SIG (Sistema de Informações Geográficas) e em trabalho de campo. Os resultados refletem que: 1) as sub-bacias hidrográficas do canal principal do Lajeado Passo dos Índios e do Lajeado Santa Maria se apresentam como as mais alteradas pelo uso do solo urbano; 2) obras de canalização, retificação e dragagem dos rios urbanos iniciaram por volta da década de 1970 e foram intensificadas nas décadas posteriores; 3) privilegiaram-se canalizações fechadas; e 4) os setores mais alterados diretamente correspondem justamente às sub-bacias com maiores intervenções decorrentes do uso do solo.
\end{abstract}

\section{Urban land use and changes in the rivers of the whatershed Lajeado Passo dos Índios, Chapecó-SC}

\section{Andrey Luis Binda*}

Maycon Fritzen**

* Professor Assistente de Geografia da Universidade Federal da Fronteira Sul UFFS, Chapecó-SC. Doutorando em Geografia pela Universidade Federal do Rio Grande do Sul - UFRGS.

** Discente do curso de Geografia da Universidade Federal da Fronteira Sul UFFS, Chapecó-SC.

\begin{abstract}
This study aims to assess the degree of indirect changes linked to urban land use and direct changes, especially in the channelization of rivers on Passo dos Indios Watershed, main urban drainage of Chapeco, West of Santa Catarina State. To achieve this objective were done revision of newspaper headlines, mapping of land use (1984-2011) and channelization works in GIS (Geographic Information System) and field work. The results reflect that: 1) the sub-basins of the main Passo dos Indios channel and the Santa Maria River are the most altered by urban land use, 2) channeling works, dredging and straightening of urban rivers started around the 1970s and was intensified in subsequent decades; 3) the channelization work privileged the construction of closed sections, and 4) the sectors most affected directly correspond precisely to the sub-basins with larger interventions arising from land use.
\end{abstract}

Geografia Ensino \& Pesquisa, vol. 17, n. 2, maio./ago. 2013 


\section{Introdução}

Alterações antrópicas na rede de drenagem podem ocorrer de duas maneiras distintas: diretamente, quando as modificações ocorrem no próprio canal fluvial por meio de atividades de mineração ou obras de engenharia tais como a construção de represas, canalizações, desvios e retificações do canal, entre outras; e, indiretamente, constituídas por modificações hidrodinâmicas decorrentes do uso e da ocupação do solo (CUNHA, 1995; PARK, 1995; GREGORY, 2006 KANG \& MARSTON, 2006).

Tais alterações são levadas ao extremo nas cidades, pois nesse ambiente a implantação de equipamentos urbanos modifica consideravelmente o ciclo hidrológico, sobretudo, pela redução da infiltração e pelo aumento do escoamento superficial, que provoca constantemente casos de inundações urbanas (TUCCI, 2003a; BOTELHO, 2011). Devido a esse fato, são executadas obras de retificações e canalizações que visam, além de ampliar a ocupação das áreas marginais, aumentar a capacidade dos canais e a eficiência do escoamento, embora muitas vezes essas medidas, além de custosas, apenas transfiram o problema, isso quando não contribuem para o aumento da magnitude e da frequência das inundações (TUCCI, 2003a; BOTELHO e SILVA, 2004; BOTELHO, 2011).

Tucci (2003b) exemplifica esse fato citando que, com o início da ocupação urbana no baixo curso de uma bacia hidrográfica, os pontos de inundações estão, normalmente, relacionados a aspectos naturais da morfologia fluvial. Buscando minimizar o efeito dessas inundações, esses trechos são retificados e canalizados, aumentando o pico de vazão a jusante (isso sem considerar que, muitas vezes, essas obras causam represamento à montante). Com a expansão da cidade em direção ao médio e alto curso da bacia hidrográfica, terrenos alagadiços são aterrados e impermeabilizados e novas canalizações contribuem para a rápida transferência d'água, que induz, novamente, inundações no trecho jusante.

Além disso, essas obras fazem com que os canais percam suas características naturais, modificando as seções transversais e o perfil longitudinal (VIEIRA \& CUNHA, 2006). A retificação de canais fluviais envolve a remoção das sinuosidades mediante a construção de um canal artificial com características geométricas distintas daquelas esculpidas pela ação fluvial (ASSUMPÇÃO e MARÇAL, 2012). Quase sempre associado com a retificação, a canalização corresponde, por sua vez, ao alargamento e ao aprofundamento do canal com posterior recobrimento do leito, das margens ou do canal todo com placas de concreto. Outra forma de alteração direta, comum em rios urbanos, está vinculada a programas de dragagens, obras que visam a remoção da vegetação e dos sedimentos do interior do canal (CUNHA, 1995).

Todas essas intervenções diretas promovem alterações não apenas no padrão, na morfologia e no gradiente do canal, mas também na rugosidade do leito e no nível de base, afetando decisivamente a dinâmica hidrossedimentológica (CUNHA, 1995). Em decorrência disso se ensejam, portanto, ajustes no sistema hidrográfico, tais como a retomada erosiva nos afluentes, erosão marginal, aumento no aporte de sedimentos e assoreamento da calha fluvial (CUNHA, 1995). Aliada a essas alterações, inclui-se, ainda, a perda da qualidade d'água decorrente do lançamento indevido de lixo e de esgotos domésticos e industriais (TUCCI, 2003a; TUCCI, 2003b; BOTELHO, 2011).

Nesse sentido, o presente trabalho busca avaliar as alterações indiretas vinculadas ao uso

Geografia Ensino \& Pesquisa, v. 17, n. 2 p. $243-259$, maio/ago. 2013

Uso do solo urbano e alterações na rede de drenagem da bacia hidrográfica do Lajeado Passo... do solo na Bacia Hidrográfica do Lajeado Passo dos Índios (BHLPI) e as diretas, sobretudo na canalização dos rios urbanos. É importante salientar que a BHLPI constitui a principal bacia hidrográfica urbana de Chapecó, uma cidade de porte médio localizada na mesorregião oeste do estado de Santa Catarina. Ademais, a ocupação da bacia vem ocorrendo desde 1920 com a implantação do primeiro núcleo de colonização, chamado, na época, de Vila Passo dos Índios (em alusão à hidrografia) (ZENI e JACOSKI, 2007). Com o passar dos anos e, principalmente, a partir da década de 1970, a expansão urbana vinculada à implantação de agroindústrias (NASCIMENTO 
et al., 2012) promoveu o aumento da pressão sobre os cursos d'água, que passaram a ser modificados por meio de obras de engenharia, para evitar os constantes casos de inundações (BINDA et al., 2012), além do fato de mudanças no uso do solo. Diante disso, é de suma importância o estudo de bacias hidrográficas em áreas urbanas, pois, conforme Boscardin (2008), esse conceito tem sido deixado de lado em muitas cidades, principalmente pelo alto grau de antropização, que, muitas vezes, torna os rios “invisíveis” à população (BOTELHO, 2011).

\section{Materiais e métodos}

\section{Localização e Características Gerais da Área de Estudo}

A BHLPI está inserida geograficamente no município de Chapecó, mesorregião oeste do estado de Santa Catarina (Figura 1) e apresenta elevada importância pelo fato de drenar grande parte da área urbana. Geomorfologicamente, a bacia encontra-se no Planalto Catarinense, mais especificamente no Planalto Oeste da Bacia Hidrográfica do Rio Uruguai, cujos rios apresentam lineamentos predominantemente E-W, SW-NE e N-S (PELUSO JÚNIOR, 1986).

Figura 1 - Localização da BHLPI.

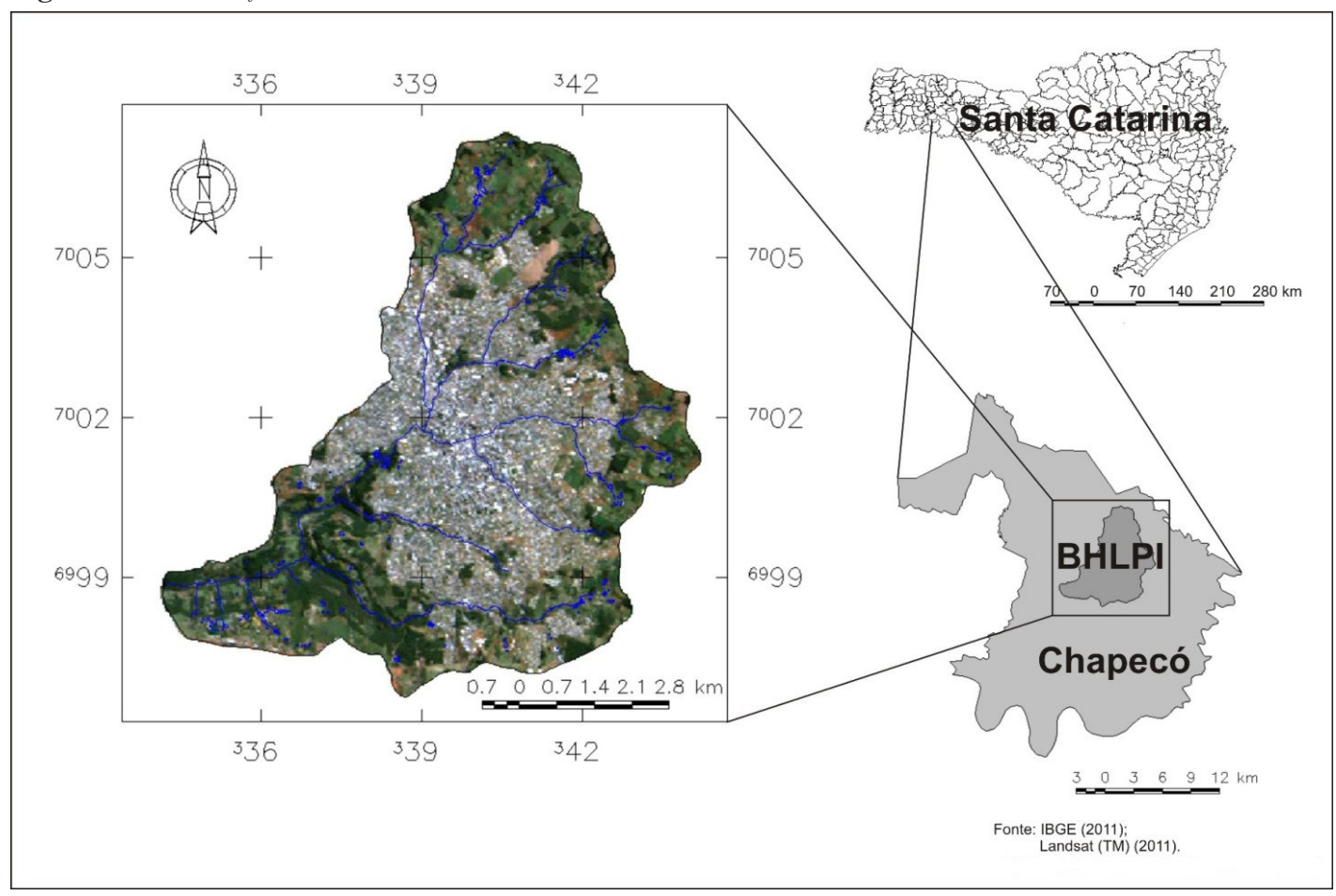

Fonte: elaborado pelo autor, 2013.

As rochas aflorantes na área pertencem à Formação Serra Geral, correspondendo, mais especificamente, a riodacitos e basaltos (SCHEIBE, 1986; NARDY, 1995) pertencentes, respectivamente: 1) à unidade ácida (Tipo Chapecó), que pode ser encontrada ao longo do médio e alto curso da bacia, onde predominam terrenos com baixa dissecação e declividades inferiores a $12 \%$, e 2) à unidade básica inferior, que ocorrem, sobretudo, no baixo curso, local onde prevalece Geografia Ensino \& Pesquisa, v. 17, n.2 p. 243-259, maio/ago. 2013 alta dissecação e declividades superiores a 30\%. As altitudes na bacia variam de $480 \mathrm{~m}$ nas proximidades da foz a 820 m nos divisores d'água, junto à Bacia Hidrográfica do Rio Irani.

Binda, A. L; Fritzen, M.

O clima é caracterizado como Subtropical Úmido ou Mesotérmico do Tipo Temperado, com temperatura média anual de $19,6^{\circ} \mathrm{C}$, ocorrência frequente de mínimas 
próximas a $0^{\circ} \mathrm{C}$ e geadas ocasionadas pela passagem de frentes frias na região no inverno. A precipitação média anual é de cerca de $2.611 \mathrm{~mm}$ distribuída regularmente ao longo do ano, embora os fenômenos El Niño e La Niña influenciem decisivamente em desvios positivos e negativos, respectivamente (NIMER, 1989; MENDONÇA \& DANNI-OLIVEIRA, 2007; PREFEITURA MUNICIPAL DE CHAPECÓ, 2011).

\section{Descrição da Pesquisa}

Para avaliar as intervenções indiretas decorrentes do uso e da ocupação do solo urbano e as alterações diretas na rede de drenagem da BHLPI, procedeu-se à aplicação de diferentes técnicas, que incluíram a revisão de manchetes de jornais, mapeamentos em ambiente SIG (Sistema de Informações Geográficas) e trabalho de campo, atividades as quais serão melhor descritas abaixo.

A consulta em jornais teve como foco as manchetes do período de 1980 a 2010 (embora tenham sido levantadas informações em jornais descontínuos anteriores) e que apresentavam informações sobre obras diretas nos canais fluviais urbanos de Chapecó, sobretudo, no que tange a canalizações e a dragagens dos leitos fluviais. Para tanto, realizou-se levantamento histórico em jornais locais impressos (Correio do Sul, Folha d'Oeste, Diário da Manhã e Diário do Iguaçu) - disponíveis na Biblioteca Pública Municipal de Chapecó-SC "Neiva Maria Andreatta Costella" e no Centro de Memória do Oeste Catarinense (CEON/Unochapecó).

A caracterização da BHLPI foi realizada aplicando técnicas de geoprocessamento. O software empregado na manipulação das informações vetoriais e matriciais e na elaboração

1 Disponível para download em: <http://www.dpi.inpe.br/ spring/>.

${ }^{2}$ Disponível em: $<$ http://www. chapeco.sc.gov.br/secretarias/ secretaria-de-planejamento/ down loads.html>. Acesso em: 12 dez. 2011.

3 Disponível em: < http:// ciram.epagri.sc.gov.br/ mapoteca/>. Acesso em: 23 abr. 2012.

4 Disponível para download em: <http://www.google.com. br/earth>.

${ }^{5}$ Disponível em: <http://www. dgi.inpe.br/CDSR/>. Acesso em: 5 fev. 2013.

Geografia Ensino \& Pesquisa, v. 17, n. 2 p. $243-259$, maio/ago. 2013

Uso do solo urbano e alterações na rede de drenagem da bacia hidrográfica do Lajeado Passo... das cartas temáticas foi o SPRING ${ }^{1}$ - INPEC Versão 5.2.1 - Sistema de Processamento de Informações Georreferenciadas (Copyright - Instituto Nacional de Pesquisas Espaciais INPE), desenvolvido pela Divisão de Processamento de Imagens - DPI do Instituto Nacional de Pesquisas Espaciais (INPE). Os dados utilizados como base corresponderam: ao banco de dados vetoriais da sede urbana de Chapecó (Prefeitura Municipal de Chapecó-SC²); a carta topográfica digital de Chapecó (SG-22-Y-C-III-2 MI-2886-2) na escala de 1:50.000, editada pela Diretoria de Serviço Geográfico do Exército e obtida junto à Mapoteca Topográfica Digital de Santa Catarina (EPAGRI/IBGE, 2004 $)$; a cenas obtidas no software Google Earth ${ }^{4}$; e a duas imagens do satélite Landsat $5(\mathrm{TM})^{5}$ de 22 de setembro de 1984 e de $1^{\circ}$ de setembro de 2011.

A partir dos dados vetoriais procedeu-se à importação deles como planos de informação para o banco de dados criado no software SPRING. Posteriormente foi atualizada a rede de drenagem da BHLPI, utilizando para isso as cenas do software Google Earth, devidamente georreferenciadas, atribuindo três classes hidrográficas: perenes, intermitentes e lagos/açudes. A delimitação da BHLPI e de suas sub-bacias hidrográficas foi realizada a partir da definição da linha dos divisores de água (COELHO NETTO e AVELAR, 2009).

As cartas de uso do solo foram confeccionadas utilizando três classes: campos/cultivos diversos, vegetação de porte médio/alto e densificação urbana. A definição dessas classes se deve ao fato de haver diferença nos processos hidrológicos de infiltração e de escoamento em cada uma delas. O processamento digital das imagens de satélite seguiu a rotina empregada no software SPRING, que consiste em georreferenciamento, segmentação, classificação (classificador Bhattacharya com limiar de aceitação de 75\% e análise de amostras com desempenho médio de 100\%) e mapeamento. Maiores informações sobre esse procedimento podem ser encontradas em Soares Filho et al. (2012).

$\mathrm{Na}$ elaboração da carta de alterações diretas da rede de drenagem da BHLPI foram considerados apenas os canais principais. A opção por excluir os canais menores se deveu em consequência de que, em sua maioria, eles se encontram canalizados junto à rede de drenagem pluvial ou por terem sido totalmente aterrados. Dessa forma, seguiu-se a diferenciação das intervenções 
fluviais proposta por Oliveira e Vestena (2012), com pequenas alterações na nomenclatura. Assim, foram discriminadas três classes: escoamento livre, canalização aberta e canalização fechada, conforme apresentado na Tabela 1. A avaliação das alterações diretas na rede de drenagem foi realizada por meio de trabalho de campo ao longo de toda a extensão da rede de canais.

Tabela 1 - Classes de alterações diretas na rede de drenagem da BHLPI.

\begin{tabular}{|c|c|c|}
\hline Classes & Características & Fotorepresentativa \\
\hline $\begin{array}{c}\text { Escoamento } \\
\text { Livre }\end{array}$ & $\begin{array}{c}\text { Canal sem alterações } \\
\text { aparentes nas margens e no } \\
\text { leito fluvial }\end{array}$ & \\
\hline $\begin{array}{c}\text { Canalização } \\
\text { Aberta }\end{array}$ & $\begin{array}{c}\text { Canal com margens e/ou } \\
\text { leito delimitados por obras } \\
\text { de engenharia. }\end{array}$ & \\
\hline $\begin{array}{c}\text { Canalização } \\
\text { Fechada }\end{array}$ & $\begin{array}{l}\text { Canal totalmente canalizado } \\
\text { por galerias fechadas com } \\
\text { secõ̃es quadradas/ } \\
\text { retangulares ou tubulações. }\end{array}$ & \\
\hline
\end{tabular}

Fonte: elaborado com base em Oliveira e Vestena (2012). Org. pelo autor, 2013.

\section{Resultados e discussões}

A BHLPI possui área total de 54,61 km², na qual se desenvolve uma rede hidrográfica de $164 \mathrm{~km}$, dividida em 52,61 km de canais perenes e 111,34 km canais intermitentes (Figura 2). Considerando toda a rede, obtém-se uma densidade de drenagem da ordem de $3 \mathrm{~km} / \mathrm{km}^{2}$. Deve-se, entretanto, fazer menção que esse valor possivelmente varia espacialmente na bacia, visto que Chin (2006) aponta que em áreas urbanas ocorre um aumento representativo na densidade de drenagem, aumento decorrente da implantação da rede de galerias pluviais. Lagos e açudes totalizam área de cerca de $0,33 \mathrm{~km}^{2}$ (Tabela 2).

Figura 2 - Rede hidrográfica e sub-bacias da BHLPI.

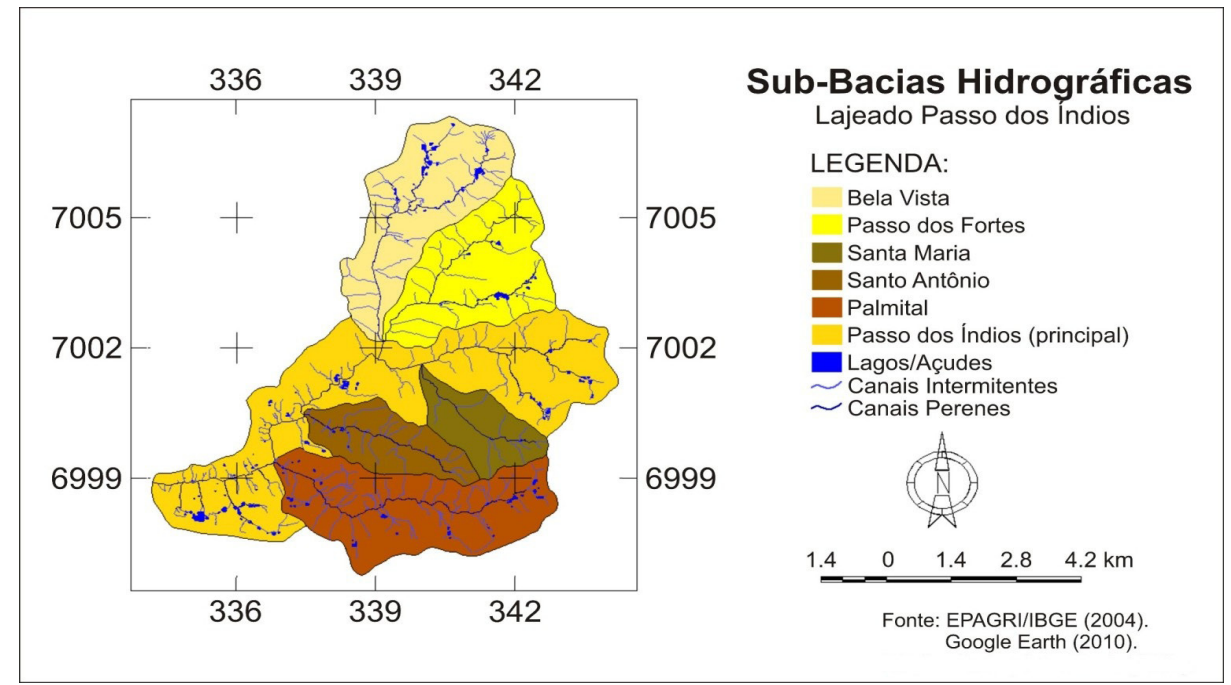

Geografia Ensino \& Pesquisa, v. 17, n. 2 p. 243-259, maio/ago. 2013

Binda, A. L; Fritzen, M. 
Tabela 2 - Hidrografia da BHLPI.

\begin{tabular}{c|c|c}
\hline Classes & $\begin{array}{c}\text { Área } \\
(\mathrm{km})\end{array}$ & $\begin{array}{c}\text { Comprimento } \\
(\mathrm{km})\end{array}$ \\
\hline Perene & - & 52,61 \\
\hline Intermitente & - & 111,34 \\
\hline Lagos/Açudes & 0,33 & - \\
\hline TOTAL & 0,33 & 163,95 \\
\hline
\end{tabular}

Fonte: medidas de classes (SPRING). Org. pelo autor, 2013.

Considerando os principais afluentes do Lajeado Passo dos Índios, dividiu-se a BHLPI em 6 sub-bacias (Figura 2), quais sejam: 1) Lajeado Santa Maria (BHLSM), que ocupa área de 3,52 $\mathrm{km}^{2}$ (6,44\%); 2) Lajeado Santo Antônio (BHLSA), com área 4,16 km² (7,62\%); 3) Lajeado Passo dos Fortes (BHLPF), que apresenta área de $8,37 \mathrm{~km}^{2}(15,33 \%)$; 4) Lajeado Bela Vista (BHLBV), que atinge $8,99 \mathrm{~km}^{2}(16,46 \%)$; 5) Lajeado Palmital (BHLPA), com total de 10,63 km² (19,47); e 6) Lajeado Passo dos Índios (Principal), com 18,94 km² (34,69\%) (Tabela 3).

Tabela 3 - Sub-bacias hidrográficas da BHLPI.

\begin{tabular}{c|c|c}
\hline $\begin{array}{c}\text { Sub-bacias } \\
\text { Hidrográficas }\end{array}$ & $\begin{array}{c}\text { Área } \\
(\mathrm{km})\end{array}$ & $\%$ \\
\hline $\begin{array}{c}\text { Lajeado } \\
\text { Santa Maria }\end{array}$ & 3,52 & 6,44 \\
\hline $\begin{array}{c}\text { Lajeado } \\
\text { Santo Antônio }\end{array}$ & 4,16 & 7,62 \\
\hline $\begin{array}{c}\text { Lajeado } \\
\text { Passo dos Fortes }\end{array}$ & 8,37 & 15,33 \\
\hline $\begin{array}{c}\text { Lajeado } \\
\text { Bela Vista }\end{array}$ & 8,99 & 16,46 \\
\hline $\begin{array}{c}\text { Lajeado } \\
\text { Palmital }\end{array}$ & 10,63 & 19,47 \\
\hline $\begin{array}{c}\text { Lajeado Passo dos } \\
\text { Indios (Principal) }\end{array}$ & 18,94 & 34,69 \\
\hline TOTAL & 54,61 & 100 \\
\hline
\end{tabular}

Fonte: medidas de classes (SPRING). Org. pelo autor, 2013.

Digno de nota é o fato de que todas as sub-bacias hidrográficas apresentadas acima apresentam uso vinculado a atividades citadinas. Mesmo assim, em virtude de o processo de crescimento da malha urbana não ser uniforme, algumas sub-bacias hidrográficas apresentaram maior ocupação urbana, o que induz a acreditar que apresentam maiores alterações decorrentes do uso do solo. Para buscar compreender essa questão, a seguir são apresentadas as alterações indiretas na BHLPI decorrente da evolução do solo, mediante a comparação de dois momentos distintos.

Geografia Ensino \& Pesquisa, v. 17, n. 2 p. $243-259$, maio/ago. 2013

Uso do solo urbano e alterações na rede de drenagem da bacia hidrográfica do Lajeado Passo...

Alterações Indiretas na BHLPI: evolução do uso do solo entre 1984 e 2011

O município de Chapecó, assim como outros municípios do país, apresentou um crescimento vertiginoso da população urbana sobretudo a partir da década de 1970. Como pode ser visto na Figura 3, a população nas décadas de 1960 e 1970, que era predominante rural, passa, nas décadas subsequentes, a ser predominantemente urbana, atingindo $92 \%$ dos 183.561 habitantes no último censo em 2010 (PREFEITURA MUNICIPAL DE CHAPECÓ, 2011). Para Nascimento et al. (2012), o aumento populacional e a concentração na área urbana de Chapecó têm suas raízes atreladas ao setor econômico, que passa a receber a implantação de unidades agroindustriais. Esse 
processo de centralização da população na cidade de Chapecó promoveu, segundo os autores supracitados, uma elevada taxa de expansão da área urbana.

Figura 3 - Crescimento populacional e local de concentração no município de Chapecó.

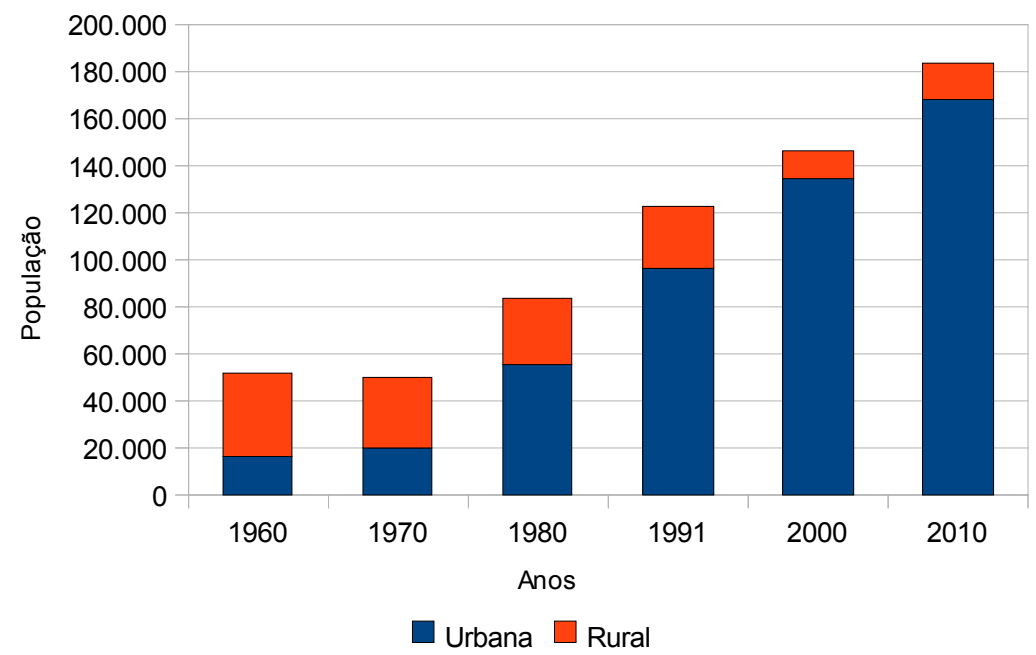

Fonte: IBGE apud Prefeitura Municipal de Chapecó-SC (2011). Org. pelo autor, 2012.

Com isso, a urbanização de Chapecó permitiu com que fossem ocupadas áreas periféricas ao centro da cidade, expandindo essa urbanização, principalmente, no âmbito da BHLPI. Deve-se enfatizar que a BHLPI efetivamente é a principal bacia hidrográfica urbana de Chapecó, perfazendo cerca de 43\% (48,56 $\left.\mathrm{km}^{2}\right)$ do atual perímetro urbano. Comparando o uso do solo da BHLPI em 1984 com 2011 (Figura 4), percebem-se modificações representativas, principalmente no que tange ao aumento da área de densificação urbana.

Em 1984, áreas cobertas por campos/cultivos representavam 71,32\% (38,95 $\left.\mathrm{km}^{2}\right)$ da BHLPI, enquanto que áreas com vegetação de porte médio/alto atingiam 12,84\% $\left(7,01 \mathrm{~km}^{2}\right) \mathrm{e}$ áreas de densificação contavam com 15,84\% $\left(8,65 \mathrm{~km}^{2}\right)$. O que se observa em 2011 foi a redução de $26,04 \%\left(14,22 \mathrm{~km}^{2}\right)$ das áreas anteriormente ocupadas por campos/cultivos diversos, que passa a representar 45,27\% $\left(24,72 \mathrm{~km}^{2}\right)$ da BHLPI. Essa redução foi compensada quase que exclusivamente pelo aumento de 24,32\% $\left(13,28 \mathrm{~km}^{2}\right)$ da área de densificação urbana, que chega, nessa ocasião, a $40,16 \%\left(21,93 \mathrm{~km}^{2}\right)$. A classe vegetação de porte médio/alto, por sua vez, obteve um incremento de 1,72\% $\left(0,94 \mathrm{~km}^{2}\right)$, fato que pode estar relacionado a atividades ligadas à silvicultura (Tabela 4).

Quando, entretanto, se observa a evolução do uso do solo nesse período de tempo, tendo como foco as sub-bacias da BHLPI, percebe-se que a distribuição das classes ocorre espacialmente e temporalmente de modo distinto. Essa ocorrência permitiu, portanto, que determinadas subbacias fossem mais modificadas pelo uso do solo urbano, o que promove alterações indiretas nas bacias, com importantes reflexos na rede de drenagem.

Entre 1984 e 2011 todas as sub-bacias da BHLPI registraram aumento expressivo da área de densificação urbana. Vinculada a esse aumento, ocorreu representativa redução da área ocupada por campos/cultivos diversos, ao passo que a classe de vegetação de médio/alto porte sofreu ora leve aumento, ora leve redução. Todo esse processo merece ser visto de modo mais detalhado. As áreas ocupadas por vegetação de médio/alto porte permaneceram ao longo desse período praticamente estáveis por se encontrarem em locais geomorfologicamente vulneráveis e de difícil ocupação urbana. Assim, portanto, a expansão urbana ocorreu, predominantemente, sobre áreas outrora ocupadas para uso agropecuário onde as condições de relevo se apresentavam mais Geografia Ensino \& Pesquisa, v. 17, n. 2 p. 243-259, maio/ago. 2013 favoráveis (Tabela 5). 
Figura 4 - Uso do solo em 1984 e 2011.

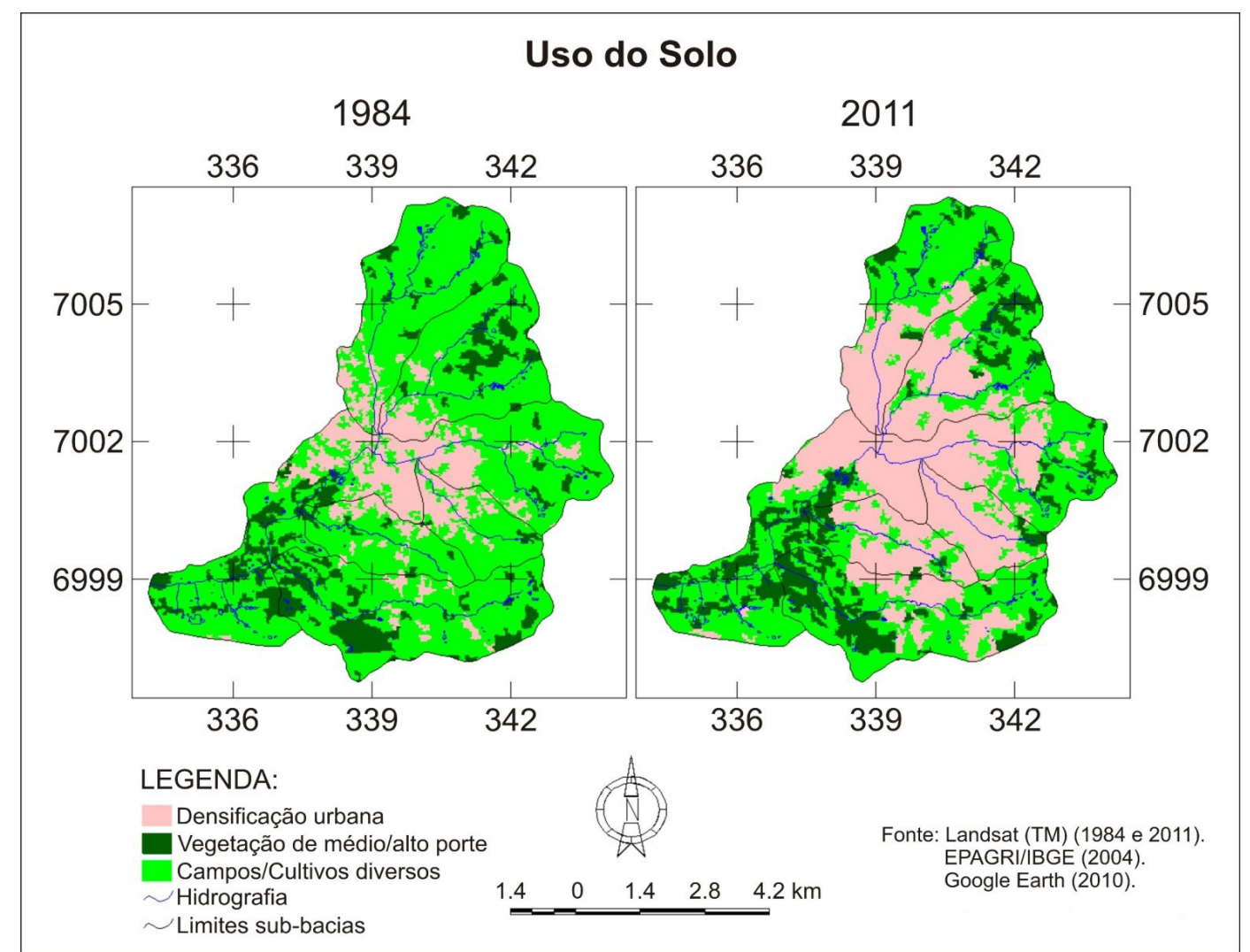

Fonte: Landsat (TM) (1984 e 2011); EPAGRI/IBGE (2004); Google Earth (2010). Org. pelo autor, 2013.

Tabela 4 - Relação entre as classes de uso de solo na BHLPI entre 1984 e $2011 .$.

\begin{tabular}{c|c|c|c|c|c|c}
\hline Classes & $\begin{array}{c}1984 \\
(\mathrm{~km})\end{array}$ & $\%$ & $\begin{array}{c}2011 \\
(\mathrm{~km})\end{array}$ & $\%$ & $\begin{array}{c}\text { Diferença } \\
(\mathrm{km})\end{array}$ & $\%$ \\
\hline $\begin{array}{c}\text { Campos/Cultivos } \\
\text { diversos }\end{array}$ & 38,95 & 71,32 & 24,72 & 45,27 & $-14,22$ & $-26,04$ \\
\hline $\begin{array}{c}\text { Vegetação de porte } \\
\text { médio/alto }\end{array}$ & 7,01 & 12,84 & 7,95 & 14,56 & 0,94 & 1,72 \\
\hline $\begin{array}{c}\text { Densificasão } \\
\text { urbana }\end{array}$ & 8,65 & 15,84 & 21,93 & 40,16 & 13,28 & 24,32 \\
\hline
\end{tabular}

Fonte: medidas de classes (SPRING). Org. pelo autor, 2013.

Nesse sentido, é possível visualizar quatro momentos distintos (Tabela 5):

- a BHLSM e a BHLPI (Principal) apresentam-se, desde 1984, como os principais eixos de expansão da área urbana de Chapecó, fato que permite discriminá-las como as sub-bacias com maior intervenção antrópica. Em 1984, áreas de densificação urbana correspondiam a 31,60\% $(1,11$ km²) na BHLSM e 23,82\% (2,34 $\left.\mathrm{km}^{2}\right)$ na BHLPI (Principal), passando, em 2011, respectivamente, a 79,75\% $\left(2,81 \mathrm{~km}^{2}\right)$ e a $39,73\left(7,52 \mathrm{~km}^{2}\right)$. Diga-se, de passagem, que o valor referente à BHLPI (Principal) se refere a toda a extensão do canal principal, o que não reflete nitidamente as intervenções da urbanização, que se concentra, exclusivamente, no alto/médio curso, onde a pressão do uso do solo é maior;

- a BHLSA corresponde, possivelmente, a um segundo momento na expansão da malha

Geografia Ensino \& Pesquisa, v. 17, n.2 p. $243-259$, maio/ago. 2013

Uso do solo urbano e alterações na rede de drenagem da bacia hidrográfica do Lajeado Passo...

$250 \quad$ ISSN $2236-4994$ urbana de Chapecó, visto que, em 1984, a área de densificação urbana correspondia a 18,36\% (0,76 $\left.\mathrm{km}^{2}\right)$, atingindo em 2011 64,15\% (2,67 km²);

- a BHLBV e BHLPF representam, por sua vez, um terceiro momento da ocupação urbana, visto que, em 1984, a área de densificação urbana perfazia, respectivamente, 9,62\% $\left(0,86 \mathrm{~km}^{2}\right)$ e 10,79\% (0,90 km²), quantificando, em 2011, 36,70\% $\left(3,30 \mathrm{~km}^{2}\right)$ e 40,18\% $\left(3,36 \mathrm{~km}^{2}\right)$. Devese enfatizar que essas duas sub-bacias provavelmente continuarão futuramente como um dos principais eixos de expansão da cidade, expansão atraída pela instalação de equipamentos urbanos, 
como, por exemplo, um shopping center;

- um último e atual momento de ocupação urbana nas sub-bacias da BHLPI corresponde ao que vem ocorrendo na BHLPA. Em 1984, a área com uso urbano representava 5,08\% (0,54 $\left.\mathrm{km}^{2}\right)$, totalizando, em 2011, 22,41\% $\left(2,38 \mathrm{~km}^{2}\right)$. A presença de duas unidades educacionais representativas nesse local tem promovido o surgimento desse novo eixo, além do fato da criação de novos loteamentos e unidades residenciais vinculadas a programas populares de habitação.

Tabela 5 - Uso do solo nas sub-bacias da BHLPI em 1984 e 2011.

\begin{tabular}{|c|c|c|c|c|c|c|c|c|c|c|c|c|c|c|c|}
\hline \multirow[t]{2}{*}{ Ano } & \multirow[t]{2}{*}{ Classe } & \multicolumn{2}{|c|}{$\begin{array}{c}\text { Lajeado } \\
\text { Santa } \\
\text { Maria }\end{array}$} & \multicolumn{2}{|c|}{$\begin{array}{c}\text { Lajeado } \\
\text { Santo } \\
\text { Antônio }\end{array}$} & \multicolumn{2}{|c|}{$\begin{array}{c}\text { Lajeado } \\
\text { Passo dos } \\
\text { Fortes }\end{array}$} & \multicolumn{2}{|c|}{$\begin{array}{c}\text { Lajeado } \\
\text { Bela } \\
\text { Vista }\end{array}$} & \multicolumn{2}{|c|}{$\begin{array}{l}\text { Lajeado } \\
\text { Palmital }\end{array}$} & \multicolumn{2}{|c|}{$\begin{array}{c}\text { Lajeado } \\
\text { Passodos } \\
\text { Índios } \\
\text { (Principal) }\end{array}$} & \multicolumn{2}{|c|}{ TOTAL } \\
\hline & & $\mathrm{km}$ & $\%$ & $\mathrm{~km}$ & $\%$ & $\mathrm{~km}$ & $\%$ & $\mathrm{~km}$ & $\%$ & $\mathrm{~km}$ & $\%$ & $\mathrm{~km}$ & $\%$ & $\mathrm{~km}$ & $\%$ \\
\hline \multirow{3}{*}{1984} & $\begin{array}{c}\text { Campos/Cultivos } \\
\text { diversos }\end{array}$ & 2,31 & 65,57 & 3,12 & 75,08 & 6,25 & 74,65 & 7,56 & 84,08 & 7,58 & 71,28 & 12,09 & 63,83 & 38,95 & 71,32 \\
\hline & $\begin{array}{c}\text { Vegetacão de } \\
\text { médio/alto porte }\end{array}$ & 0,10 & 2,83 & 0,27 & 6,56 & 1,22 & 14,56 & 0,57 & 6,29 & 251 & 23,64 & 234 & 12,35 & 7,01 & 12,84 \\
\hline & Densificação urbana & 1,11 & 31,60 & 0,76 & 18,36 & 0,90 & 10,79 & 0,86 & 9,62 & 0,54 & 5,08 & 4,51 & 23,82 & 8,65 & 15,84 \\
\hline \multirow{3}{*}{2011} & $\begin{array}{c}\text { Campos/Cultivos } \\
\text { diversos }\end{array}$ & 0,53 & 15,17 & 1,05 & 25,29 & 3,87 & 46,24 & 4,94 & 55,00 & 5,65 & 53,18 & 8,58 & 45,28 & 24,72 & 45,27 \\
\hline & $\begin{array}{c}\text { Vegetacâa de } \\
\text { médio/alto porte }\end{array}$ & 0,18 & 5,08 & 0,44 & 10,57 & 1,14 & 13,57 & 0,75 & 8,30 & 2,59 & 24,41 & 2,84 & 14,99 & 7,95 & 14,56 \\
\hline & Densificação urbana & 2,81 & 79,75 & 2,67 & 64,15 & 3,36 & 40,18 & 3,30 & 36,70 & 238 & 22,41 & 7,52 & 39,73 & 21,93 & 40,16 \\
\hline
\end{tabular}

Essas diferenciações têm, portanto, representado uma grande discrepância entre as classes de uso do solo nas sub-bacias do Lajeado Passo dos Índios. Diferentes autores (BOTELHO e SILVA, 2004; KONRAD \& BOOTH, 2005; BOTELHO, 2011) têm afirmado que, quando uma bacia hidrográfica com uso predominante rural passa para urbana, ocorrem diversas alterações nos processos hidrológicos, processos que podem ser basicamente sintetizados no aumento do escoamento em detrimento da infiltração, o que condiciona, muitas vezes, inundações repentinas. Como apresentado no início deste trabalho, intervenções diretas, tais como as canalizações, são realizadas no sentido de mitigar o pico de enchente. Frente a isso, levanta-se uma outra questão e que conduz a uma nova problemática, a de que se realmente uma maior taxa de ocupação urbana induz a maiores intervenções diretas no canal. Nesse sentido, busca-se, no próximo tópico, avaliar as principais formas de alterações promovidas por meio da implantação de trechos canalizados nos rios urbanos da BHLPI.

\section{Alterações Diretas na Rede de Drenagem do Lajeado Passo dos Índios}

Históricos de intervenções na BHLPI

Mediante a consulta em manchetes de jornais locais foi possível perceber que intervenções diretas na rede de drenagem da BHLPI estão, normalmente, vinculadas à implantação de obras de engenharia para mitigar casos de inundação na cidade. Binda et al. (2012) apontam, inclusive, que muitas dessas obras acabaram, posteriormente, desencadeando eventos de inundação, sobretudo, pelo subdimensionamento das seções canalizadas, que causavam o estrangulamento dos canais fluviais, acrescentando-se a isso, ainda, o fato do aumento das áreas impermeabilizadas.

Dessa forma, as primeiras alterações nos canais fluviais urbanos de Chapecó aparecem em manchetes de jornais ainda na década de 1970, mais especificamente em 1977, quando foi relatada a conclusão da canalização de um trecho fluvial do Lajeado Passo dos Índios (CORREIO DO SUL, 1977). Nesse mesmo período foi enfatizada ainda a necessidade de adequação da drenagem urbana (FOLHA D’OESTE, 1978), mediante a retificação e a canalização de trechos fluviais urbanos (Figura 5) (DIÁRIO DA MANHÃ, 1979).

Geografia Ensino \& Pesquisa, v. 17, n.2 p. 243-259, maio/ago. 2013

Binda, A. L; Fritzen, M. 
Figura 5 - Canalização no Lajeado Santa Maria.

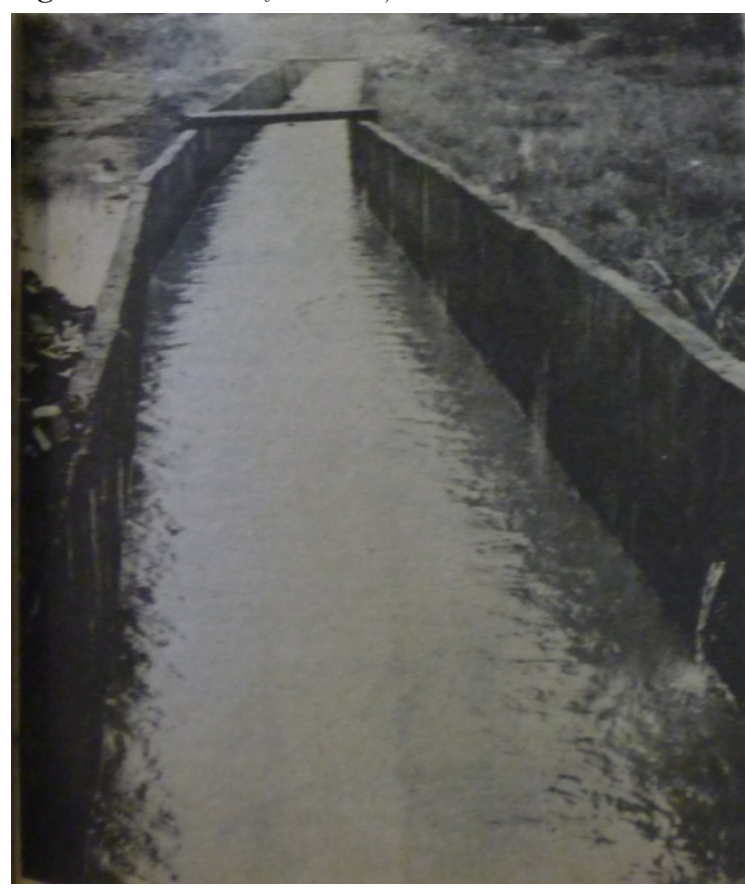

Fonte: Diário da Manhã (1979, p.1).

Como forma de mitigar os pontos de inundação ocorridos em 1983, o poder público municipal levantou recursos junto ao governo federal para a execução de obras de canalização nos Lajeados Bela Vista, Santo Antônio e Passo dos Índios (DIÁRIO DA MANHÃ, 1984). Além disso, foram realizadas obras de drenagem de terrenos alagadiços no bairro Santa Maria (BHLSM), conectando a microdrenagem diretamente ao Lajeado Santa Maria. Nessa área foram abertas ruas e implantados loteamentos (DIÁRIO DA MANHÃ, 1986a), que passariam a sofrer com casos de inundações (DIÁRIO DA MANHÃ, 1986b). Com isso foram, posteriormente, implantadas novas obras de canalização que tinham como foco mitigar a situação.

Para se ter uma ideia das intervenções diretas nos rios urbanos de Chapecó, uma manchete publicada em 1987 apresentava que a Prefeitura Municipal realizou, desde 1983, o aumento da capacidade do canal e a retificação de cerca de $9.755 \mathrm{~m}$ de rios urbanos, a canalização de 12 segmentos, totalizando $591 \mathrm{~m}$, e a implantação de $9.876 \mathrm{~m}$ de tubulação para drenagem pluvial (DIÁRIO DA MANHÃ, 1987).

Embora essas obras tivessem sido implantadas na cidade, em 1990 foi realizado novo programa de canalização dos rios urbanos de Chapecó. Isso foi reflexo do fato de que determinados setores, tais como o do trecho canalizado do Lajeado Passo dos Índios no centro da cidade (o canal outrora construído) se encontravam com a capacidade comprometida pelo assoreamento natural do rio e pela deposição de lixo, necessitando a abertura de um novo canal adjacente (DIÁRIO DA MANHÃ, 1990a; 1990b; 1990c), cujas obras iniciaram somente em 1991 (DIÁRIO DA MANHÃ, 1991a). Foi enfatizada, ainda, a continuação dos trabalhos de dragagem no Lajeado Passo dos Índios, no Santa Maria e no Passo dos Fortes, com vistas a aumentar a capacidade do canal em cerca de $30 \%$.

Esses trabalhos de dragagem foram concluídos em 1991, após a inclusão de atividades no

Geografia Ensino \& Pesquisa, v. 17, n. 2 p. $243-259$, maio/ago. 2013

Uso do solo urbano e alterações na rede de drenagem da bacia hidrográfica do Lajeado Passo...
Lajeado Bela Vista. Essas obras foram executadas utilizando uma retroescavadeira para os trechos de escoamento livre e a retirada manual em setores com canalização aberta e fechada (Figura 6a e b) (DIÁRIO DA MANHÃ, 1991b). Ainda em 1991 foi iniciada a troca e a ampliação de setores canalizados no Lajeado Santa Maria, no Passo dos Fortes e no Passo dos Índios (DIÁRIO DA MANHÃ, 1991a), obras que culminaram em um grande projeto de macrodrenagem que se estendeu até 1993 (DIÁRIO DA MANHÃ, 1993a; 1993b). Enquanto as obras de canalização 
não estivessem prontas foram realizados trabalhos semestrais de limpeza e de dragagem dos rios urbanos, como medida para evitar pontos de inundação, principalmente no Lajeado Passo dos Índios, no Santa Maria, no Passo dos Fortes e no Bela Vista (DIÁRIO DA MANHÃ, 1992; DIÁRIO DA MANHÃ, 1993a; 1993b).

Figura 6 - Limpeza de trecho com canalização aberta (esquerda) e fechada (direita).

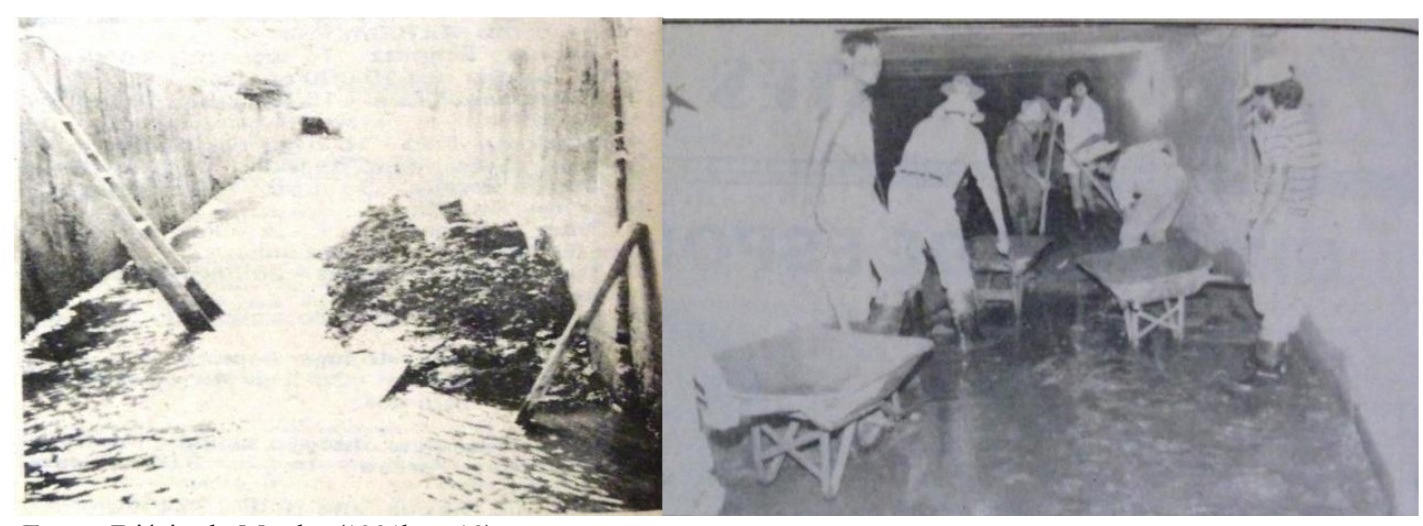

Fonte: Diário da Manhã (1991b, p.12).

Entretanto, novas obras de retificação e de canalização foram implementadas no Lajeado Passo dos Índios em 1994, cuja extensão total de trechos na cidade de Chapecó deveria chegar a aproximadamente 2.000 m (DIÁRIO DA MANHÃ, 1994; 1995a; 1995b; 1995c). Em 1996, as obras de canalização focaram o Lajeado Bela Vista e o Santa Maria (DIÁRIO DA MANHÃ, 1996a; 1996b). A partir de 2000, os rios urbanos voltam a passar por trabalhos de dragagem (Figura 7), a fim de aumentar a capacidade do canal, principalmente em trechos do Lajeado Passo dos Índios no bairro São Pedro e no Maria Goretti, e nos Lajeados Passo dos Fortes e Bela Vista nos bairros homônimos (DIÁRIO DA MANHÃ, 2000).

Figura 7 - Escavadeira hidráulica utilizada para dragagem de rio urbano.

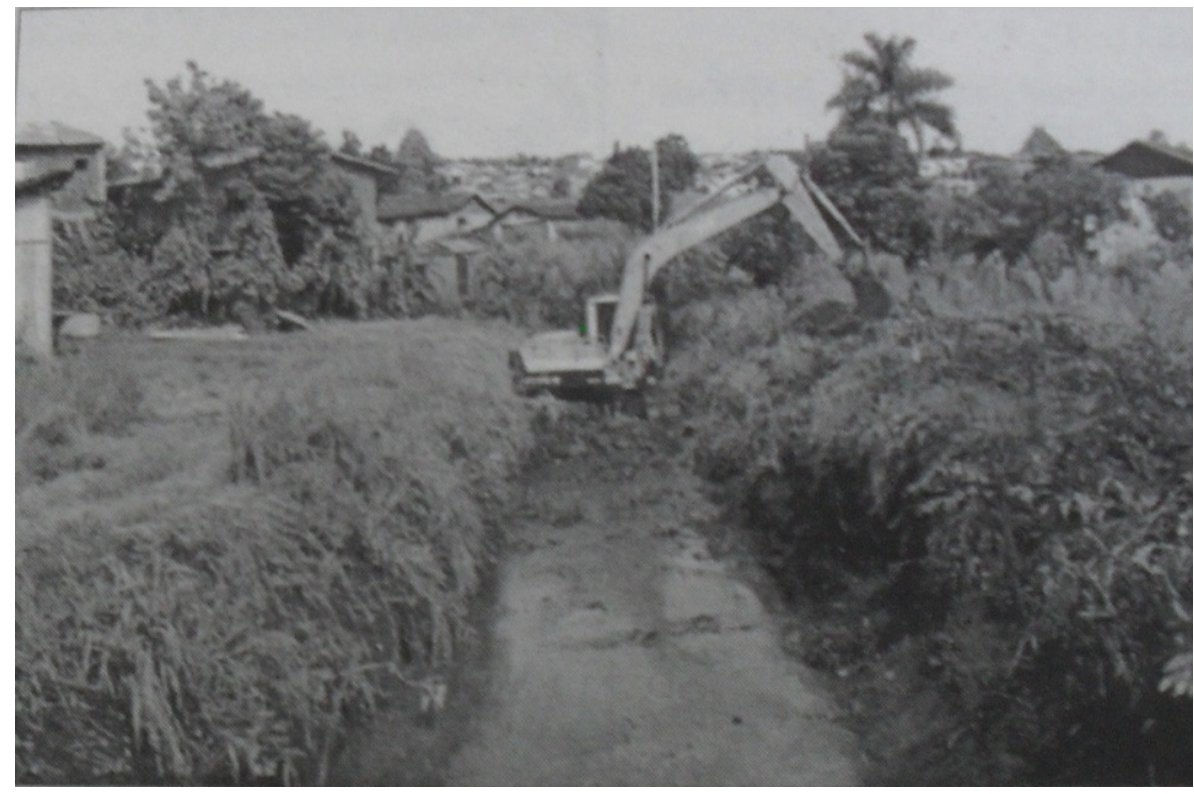

Fonte: Diário da Manhã (2000, p.6).

Geografia Ensino \& Pesquisa, v. 17, n. 2 p. 243-259, maio/ago. 2013

Em 2005 foi implantado um novo projeto ("Sangas") de recuperação dos rios de Chapecó. Dentre as ações previstas, incluíam-se a limpeza do leito e das margens dos canais e o plantio de espécies nativas e frutíferas para reconstituição da mata ciliar (DIÁRIO DO IGUAÇU, 2005). As atividades de dragagem e limpeza dos canais fluviais só foram, entretanto,

Binda, A. L; Fritzen, M. 
iniciadas em meados de 1997, com intervenções nos Lajeados Passo dos Índios, Passo dos Fortes e Bela Vista (DIÁRIO DO IGUAÇU, 2007a) e no Lajeado Santo Antônio e Palmital (DIÁRIO DO IGUAÇU, 2007b). Demonstrando a evolução desse programa de dragagem e limpeza de riachos, uma manchete do Diário do Iguaçu (2007c) noticiou que a limpeza do Lajeado Passo dos Índios chegou até a área das cabeceiras no Bairro São Pedro e que, no Lajeado Passo dos Fortes, as obras se concentravam próximas ao Ecoparque, local que veio a receber canalização em 2010 (DIÁRIO DO IGUAÇU, 2010a; 2010b).

\section{Mapeamento dos Trechos Canalizados na BHLPI}

Como foi descrito anteriormente, alterações diretas sob a forma de canalização, retificação e dragagem foram executadas em diversos momentos nas últimas três décadas. Essas obras foram realizadas nos principais canais fluviais urbanos, principalmente no Lajeado Passo dos Índios, no Santa Maria, no Passo dos Fortes e no Bela Vista e, secundariamente, no Lajeado Santo Antônio e no Palmital. O mapeamento dos trechos canalizados (Figura 8) confirma essas informações, uma vez que essa classe corresponde a, aproximadamente, 14\% $(7,37 \mathrm{~km})$ da rede principal de drenagem do BHLPI. É importante salientar que segmentos com canalização fechada correspondem à maior fatia, totalizando $13 \%(6,82 \mathrm{~km})$, enquanto que as canalizações abertas perfazem apenas $1 \%(0,55 \mathrm{~km})$. Embora os canais com escoamento livre quantifiquem cerca de $86 \%(45,24 \mathrm{~km})$ (Tabela 6), vale recordar que, possivelmente, parte desse total já deve ter sofrido alguma intervenção por meio de dragagens e de retificações, conforme exposto no item anterior.

Tabela 6 - Alterações diretas nos canais fluviais da BHLPI.

\begin{tabular}{|c|c|c|}
\hline Classes & $\begin{array}{c}\text { Comprimento } \\
(\mathrm{km})\end{array}$ & $\%$ \\
\hline Escoamento Livre & 45,24 & 85,99 \\
\hline Canalização Parcial & 0,55 & 1,05 \\
\hline Canalização Total & 6,82 & 12,96 \\
\hline TOTAL & 52,61 & 100 \\
\hline
\end{tabular}

Considerando as sub-bacias hidrográficas, percebe-se que a do Lajeado Santa Maria é, sem dúvida, a que mais passou por alterações diretas. Canalizações fechadas correspondem à totalidade das intervenções, atingindo $2.307 \mathrm{~km}$, o que corresponde a $64 \%$ da drenagem principal. O Lajeado Passo dos Índios também apresenta um grau intenso de intervenções, que perfazem $2.207 \mathrm{~m}$ de canalizações, predominantemente fechadas e que respondem por $11 \%$ da rede hidrográfica, embora se deva fazer ressalva de que a cidade se desenvolve, sobretudo, no alto/médio curso, o que leva a crer que o percentual de modificações no trecho urbano seja maior (Tabela 7). Os maiores trechos canalizados em ambas as bacias totalizam, respectivamente, $984 \mathrm{~m}$ e $989 \mathrm{~m}$, e encontram-se abaixo das ruas Domingos Baldissera, no bairro Santa Maria, e da Benjamin Constant, no centro da cidade.

Os canais fluviais do Lajeado Passo dos Fortes e do Bela Vista encontram-se num

Geografia Ensino \& Pesquisa, v. 17, n.2 p. $243-259$, maio/ago. 2013

Uso do solo urbano e alterações na rede de drenagem da bacia hidrográfica do Lajeado Passo... segundo grupo de intensidade de intervenções. Os trechos canalizados dessas bacias totalizaram, respectivamente, 1.081 e $881 \mathrm{~m}$, o que significa cerca de $12 \%$ e $9 \%$ da rede de rios. Em ambas as bacias há um maior número de canalizações fechadas que podem cobrir trechos da ordem de $670 \mathrm{~m}$ e de $840 \mathrm{~m}$ de extensão, embora possam ser encontradas canalizações abertas que atingem $411 \mathrm{~m}$ (Ecoparque) e $41 \mathrm{~m}$, respectivamente (Tabela 7). 
Figura 8 - Intervenções sob a forma de canalizações na BHLPI.

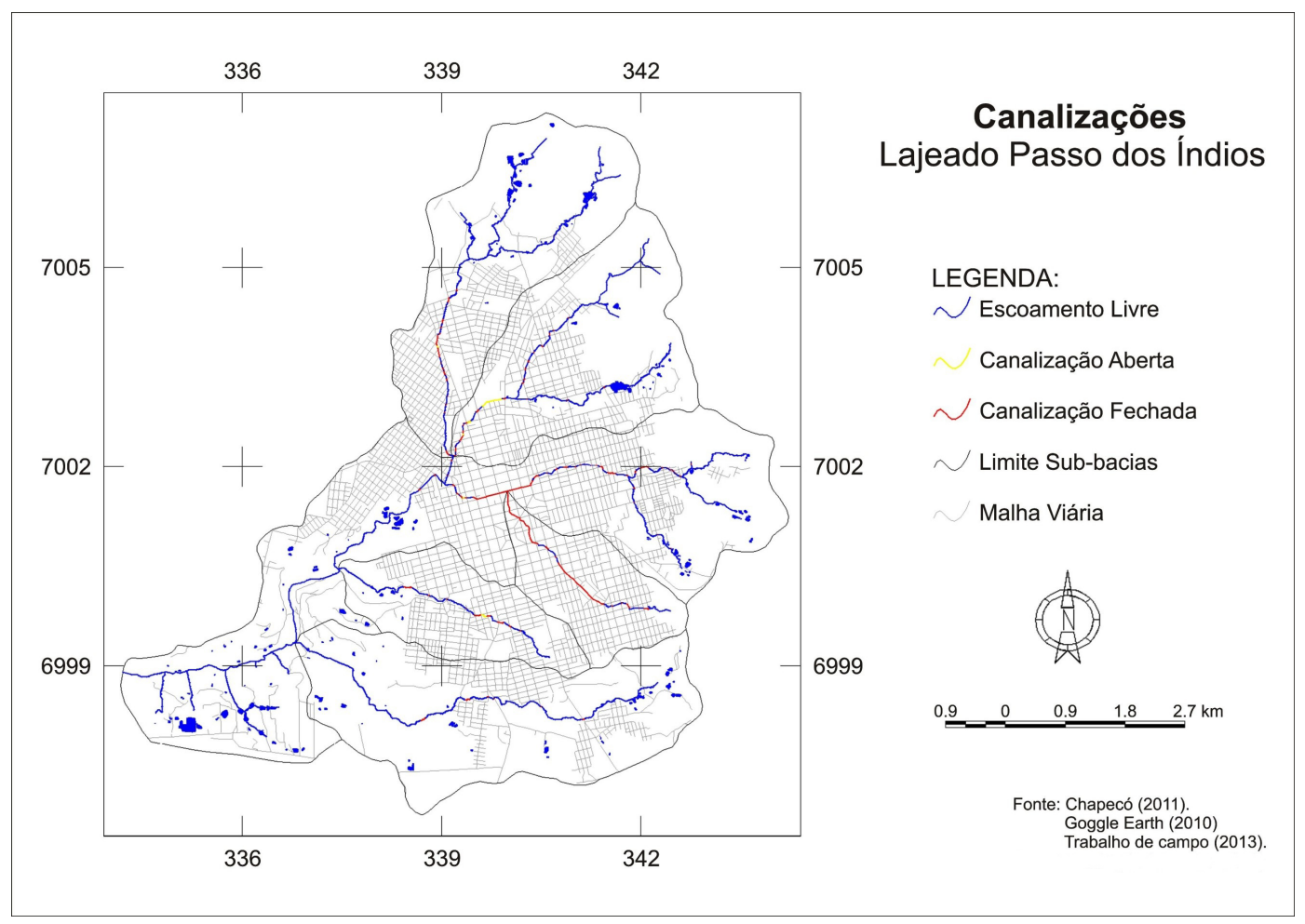

Fonte: Chapecó (2011); Google Earth (2010); Trabalho de campo (2013). Elaborado pelo autor, 2013.

Por outro lado, no Lajeado Santo Antônio e, principalmente, no Palmital, são encontradas as menores alterações relacionadas a obras de engenharia fluvial. No Lajeado Santo Antônio, embora o total de canalizações quantifique apenas $578 \mathrm{~m}$, esse valor refere-se a cerca de $15 \%$ da rede de canais, o que a coloca em segundo lugar no quesito relação entre os trechos canalizados e extensão total dos canais principais. No Lajeado Palmital, a extensão canalizada é de apenas $239 \mathrm{~m}$ ou 3\% do canal principal, o que a insere como a que apresenta o menor índice de intervenções. Assim como nas demais sub-bacias, são predominantes as canalizações fechadas, que representam 128 m no Lajeado Santo Antônio e 76 m no Lajeado Palmital. Deve-se incluir ainda um trecho com canalização aberta no Lajeado Santo Antônio, com 93 m de extensão (Tabela 7).

Tabela 7 - Características dos segmentos canalizados por sub-bacia hidrográfica.

\begin{tabular}{c|c|c|c|c|c|c|c|c}
\hline \multirow{2}{*}{$\begin{array}{c}\text { Sub-bacia } \\
\text { Hidrográfica }\end{array}$} & $\begin{array}{c}\text { Número de } \\
\text { Segmentos } \\
\text { Canalizados }\end{array}$ & \multicolumn{2}{|c|}{$\begin{array}{c}\text { Maior } \\
\text { Segmento } \\
\text { Canalizado (m) }\end{array}$} & \multicolumn{3}{|c|}{$\begin{array}{c}\text { Extensão Total } \\
\text { das Canalizações } \\
\text { (m) }\end{array}$} & \multirow{2}{*}{$\%$} \\
\cline { 2 - 7 } & Aberta & Fechada & Aberta & Fechada & Aberta & Fechada & Total & \\
\hline Santa Maria & - & 10 & - & 984 & - & 2.307 & 2.307 & 64 \\
\hline Santo Antônio & 1 & 9 & 93 & 128 & 93 & 485 & 578 & 15 \\
\hline $\begin{array}{c}\text { Passo dos } \\
\text { Fortes }\end{array}$ & 3 & 27 & 326 & 104 & 411 & 670 & 1.081 & 12 \\
\hline $\begin{array}{c}\text { Bela Vista } \\
\text { Palmital }\end{array}$ & 1 & 22 & 41 & 158 & 41 & 840 & 881 & 9 \\
\hline $\begin{array}{c}\text { Passodos Índios } \\
\text { (Principal) }\end{array}$ & 1 & 38 & 40 & 989 & 40 & 2.167 & 2.207 & 11 \\
\hline
\end{tabular}

Geografia Ensino \& Pesquisa, v. 17, n. 2 p. 243-259, maio/ago. 2013

Binda, A. L; Fritzen, M.

Fonte: medidas de classes (SPRING). Org. pelo autor, 2013. 
Em geral, os trechos com canalização fechada correspondem, principalmente, a travessias de ruas. Há, entretanto, outras situações, tais como os já citados trechos que se encontram abaixo de determinadas ruas e, inclusive, casos onde construções inteiras foram executadas sobre os canais fluviais. Casos como este foram observados no Lajeado Passo dos Fortes (Figura 9), no Bela Vista, no Santo Antônio e no Passo dos Índios.

Figura 9 - Trecho com canalização fechada imediatamente abaixo de prédio no Lajeado Passo dos Fortes.

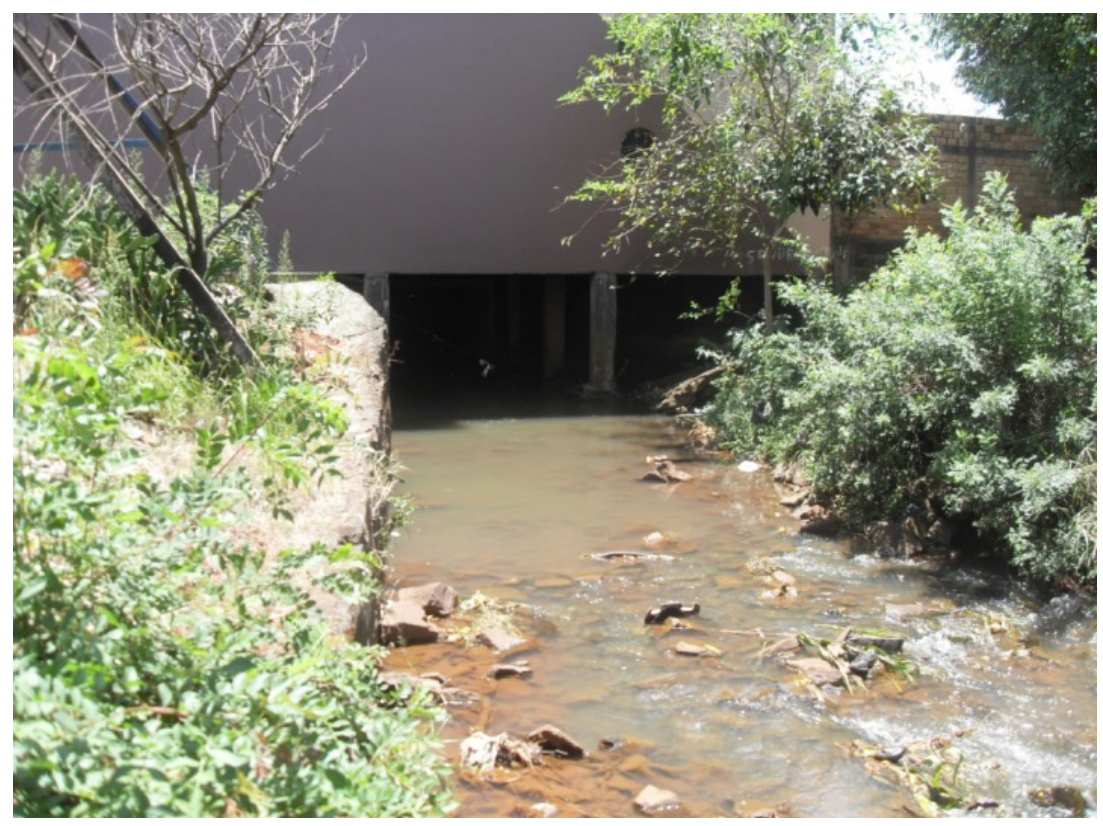

Fonte: Arquivo pessoal. Foto: autor (2013).

\section{Considerações finais}

O processo de crescimento e de expansão da área urbana de Chapecó tem, ao longo dos últimos anos, contribuído para a ocupação e a intensificação urbana em diferentes sub-bacias hidrográficas do Lajeado Passo dos Índios. Isso tem resultado tanto em alterações diretas como indiretas, alterações que têm promovido, além da modificação dos rios urbanos, a perda da qualidade das águas superficiais. Cabe ressaltar, entretanto, que a ocupação não ocorre de modo homogêneo, o que promove que determinadas sub-bacias estejam condicionadas a maior pressão do crescimento urbano.

Dessa forma, fica claro que os setores mais alterados, seja indiretamente, quanto diretamente, correspondem àqueles de ocupação mais antiga e de adensamento populacional, que correspondem, especificamente, à BHLPI (Principal) e BHLSM. Nesses locais, os cursos fluviais se encontram canalizados preferencialmente por seções fechadas, o que contribui com a afirmação de Botelho (2011), de que os rios acabam se tornando "invisíveis" à população, sendo vistos, na maioria das vezes, como locais problemáticos por motivo de inundações e de vetores de doenças. Secundariamente, aparecem as BHLPF, BHLBV e BHLSA, nas quais a ocupação tem sido intensificada nos últimos anos e onde obras de canalização têm sido realizadas. A BHLPA, por sua vez, corresponde a um novo momento de expansão urbana de Chapecó. Esse fato a coloca como a sub-bacia com menores intervenções e, portanto, local estratégico para uma ocupação diferenciada.

Geografia Ensino \& Pesquisa, v. 17, n. 2 p. $243-259$, maio/ago. 2013

Uso do solo urbano e alterações na rede de drenagem da bacia hidrográfica do Lajeado Passo...
Considerando o pressuposto apresentado por Botelho (2011, p. 93), segundo o qual “[...] a ideia de 'desconstruir' cidades é inconcebível e ilusória, pois não podemos deixar de construir moradias, asfaltar ruas, erguer centros empresariais, etc. [...]”, então urgem políticas públicas que considerem os aspectos da dinâmica hidrológica durante a expansão urbana. As informações apresentadas neste trabalho podem contribuir para a gestão dos rios urbanos da cidade de Chapecó. Quanto às sub- 
bacias com menor intervenção, sobre elas se deve refletir para instituir novas formas de ocupação e que privilegiem a dinâmica natural na bacia hidrográfica, além de limitar a ocupação das áreas marginais e dos terrenos alagadiços, os quais podem ser utilizados para fins de recreação, conforme apontamentos realizados por Tucci (2003b). Quanto a sub-bacias com maior alteração antrópica, Cunha (2007) e Botelho (2011) apresentam como solução a implementação de práticas de recuperação e de renaturalização de rios urbanos. Apontam as autoras que tais práticas exigem medidas atreladas a uma concepção holística de bacia hidrográfica.

\section{Referências}

ASSUMPÇÃO, A. P.; MARÇAL, M. S. Retificação dos canais fluviais e mudanças geomorfológicas na planície do Rio Macaé-RJ. Revista de Geografia (UFPE), v. 29, n. 3, p.1936, 2012.

BINDA, A.L.; BUFFON, E.A.M.; FRITZEN, M. Análise espaço-temporal dos casos de inundações e de alagamentos registrados na cidade de Chapecó-SC (1980-2010). Ra E'Ga, v. 26, p. 35-50, 2012.

BOSCARDIN, C. R. A gestão de bacias hidrográficas urbanas: a experiência de Curitiba.

Dissertação (Mestrado em Gestão Urbana). Curitiba: PUC, 2008. 222f.

BOTELHO, R. G. M. Bacias hidrográficas urbanas. In: GUERRA, A. J. T. (Org.).

Geomorfologia urbana. Rio de Janeiro: Bertrand Brasil, 2011. p. 71-115.

BOTELHO, R. G. M.; SILVA, A. S. Bacia hidrográfica e qualidade ambiental. In: VITTE, A. C.; GUERRA, A. J. T. Reflexões sobre a geografia física no Brasil. Rio de Janeiro: Bertrand Brasil, 2004.

CHIN, A. Urban transformation of river landscape in a global context. Geomorphology, v. 79, p. 460-487, 2006.

COELHO NET'TO, A. L.; AVELAR, A. S. Hidrologia de encosta na interface com a geomorfologia. In: CUNHA, S. B.; GUERRA, A. J. T. (Orgs.). Geomorfologia: exercícios, técnicas e aplicações. 3. ed. Rio de Janeiro: Bertrand Brasil, 2009. p. 103-138.

CUNHA, S. B. Geomorfologia fluvial. In: GUERRA, A. J. T.; CUNHA, S. B. (Org.). Geomorfologia: uma atualização de bases e conceitos. 3. ed. Rio de Janeiro: Bertrand Brasil, 1995. p. 211-252.

CUNHA, S. B. Canais fluviais e a questão ambiental. In: CUNHA, S. B.; GUERRA, A. J. T. (Org.). A questão ambiental: diferentes abordagens. 3. ed. Rio de Janeiro: Bertrand Brasil, 2007. p. 219-238.

CUNHA, S. B.; GUERRA, A. J. T. Degradação ambiental. In: GUERRA, A. J. T.; CUNHA, S. B.

(Org.). Geomorfologia e meio ambiente. 10. ed. Rio de Janeiro: Bertrand Brasil, 2011. p. 337-379.

CORREIO DO SUL. Canal Passo dos Índios tem Conclusão Parcial. Correio do Sul, Chapecó-SC. Ano I. N 5, p. 12. 10 de julho de 1977.

DIÁRIO DA MANHÃ. Novo Lance de Concreto sobre o Riacho Santa Maria e Mais 40 Mil Metros de Enlevamento nos Passeios. Diário da Manhã, Chapecó-SC, Ano I. N 17, p. 1, 26 de outubro de 1979.

DIÁRIO DA MANHÃ. Prefeito foi a Brasilia buscar recursos para canalização. Diário da Manhã, Chapecó-SC, ano $V, n^{\circ} 227$, p. $18,7-8$ set. 1984.

DIÁRIO DA MANHÃ. [Matéria sem título]. Diário da Manhã, Chapecó-SC, ano VII, no 143, p. 1, 7 maio 1986a.

DIÁRIO DA MANHÃ. Chuva destruiu 4 mil toneladas de trigo. Diário da Manhã, Chapecó-SC, ano VIII, no 21, p.11, 6 nov. 1986b.

DIÁRIO DA MANHÃ. Prefeitura investe na canalização de riachos. Diário da Manhã, Chapecó-SC, ano VIII, nº 189,p. 3, 11/12 jul. 1987.

DIÁRIO DA MANHÃ. Canais são dragados para prevenir cheias. Diário da Manhã, Chapecó-SC, ano XII, no 11,p. 1, 23 out. 1990a.

Geografia Ensino \& Pesquisa, v. 17, n. 2 p. 243-259, maio/ago. 2013

Binda, A. L; Fritzen, M. 
DIÁRIO DA MANHÃ. Novo canal - a solução contra enchentes. Diário da Manhã Chapecó-SC, ano XII, n ${ }^{\circ} 6$, p. 1,16 out. 1990b.

DIÁRIO DA MANHÃ. Bairro Santa Maria recebe obras de infra-estrutura. Diário da Manhã Chapecó-SC, ano XI, no 183, p. 5,7/8jul. 1990c.

DIÁRIODA MANHÃ. Canalização vai ser ampliada. Diário da Manhã ChapecóSC, ano XII, nº 153, p. 1, 7 maio 1991a.

DIÁRIO DA MANHÃ (1991b). Limpeza dos canais. Diário da Manhã, Chapecó-SC, ano XII, nº 135, p. 12,10 abr. $1991 b$.

DIÁRIODA MANHÃ. Limpeza de riachos Diário da Manhã ChapecóSC, ano XIII, no 97,p. 1,27 fev. 1992.

DIÁRIO DA MANHÃ. Chapecó livre das ameaças de enchentes e alagamentos. Diário da Manhã, Chapecó-SC, ano XVI, no 103, p. 16, 7/8 ago. 1993a.

DIÁRIO DA MANHÃ. Prefeitura reinicia obras de canalização que vão livrar Chapecó dos alagamentos. Diário da Manhã, Chapecó-SC, ano XIV, no 154, p. 7, 17 jun. 1993b.

DIÁRIO DA MANHÃ. Conclusão do canal Benjamin Constant vai impedir inundação. Diário da Manhã Chapecó-SC, ano XV, nº 136, p. 16, 5 maio 1994.

DIÁRIO DA MANHÃ. Prossegue trabalho de macrodrenagem para evitar inundações. Diário da Manhã Chapecó-SC, ano 16, n 77, p. 1,26 jan. 1995a.

DIÁRIO DA MANHÃ. L impeza de valas e bueiros para evitar inundações. Diário da Manhã, ChapecóSC, ano 16, n 84 ,p. 9, 4/5 fev. $1995 \mathrm{~b}$.

DIÁRIODA MANHÃ. Chapecó sem alagamentos. Diário da Manhã, Chapecó-SC, ano 17, nº 29, p. 7 , 22 nov. 1995 c.

DIÁRIO DA MANHÃ. Programa de Macrodrenagem é prioridade em Chapecó. Diário da Manhã, Chapecó-SC, ano 17, n 118, p. 8, 29 mar. 1996a.

DIÁRIO DA MANHÃ. Nova obra de canalização no Lajeado Santa Maria. Diário da Manhã, Chapecó-SC, ano 18, ñ 1, p. 8, 9 out. 1996b.

DIÁRIO DA MANHÃ. Prefeitura limpa canais e riachos. Diário da Manhã, Chapecó-SC, ano 21, no 87, p. 6,18 fev. 2000.

DIÁRIO DO IGUAÇU. Recuperação e preservação dos riachos. Diário do IguaÇU, Chapecó-SC, ano 9, no 2237, p.11,22 abr. 2005.

DIÁRIO DO IGUAÇU. Prefeitura retoma limpeza de rios em Chapecó. Diário do IguaÇU, ChapecóSC, ano 9, n 2771, p. 11, 8 fev. 2007 .

DIÁRIO DO IGUAÇU.L Limpeza abrange seis rios de Chapecó. Diário do IguaÇU, Chapecó-SC, ano 9, no 2785, p. 14, 27 fev. $2007 \mathrm{~b}$.

DIÁRIO DO IGUAÇU. Até maio seis reios devem ser limpos. Diário do IguaÇU, Chapecó-SC, ano 10, no 2814, p. 12, 2 abr. 2007c.

DIÁRIO DO IGUAÇU. Foco de 2010 será drenagem urbana. Diário do IguaÇU, Chapecó-SC, ano 12 no 3668, p. 12, 25 jan. 2010 a.

DIÁRIO DO IGUAÇU. Começa drenagem do Ecoparque. Diário do IguaÇU, Chapecó-SC, ano 14,

Geografia Ensino \& Pesquisa, v. 17, n.2 p. $243-259$, maio/ago. 2013

Uso do solo urbano e alterações na rede de drenagem da bacia hidrográfica do Lajeado Passo... n 3805 , p. 21, 10/11 jul. 2010b.

FOLHA D’OESTE. Passo dos Índios será canalizado. Folha d'Oeste, Chapecó-SC, ano XIII, n ${ }^{\circ}$ 672, p. 17, 15 abr. 1978.

GREGORY, K. J. The human role in changing river channels. Geomorphology, v. 79, p. 172-191, 2006.

KANG, R. S.; MARSTON, R. A. Geomorphic effects of rural-to-urban land use conversion on three streams in the central red bed plains of Oklahoma. Geomorphology, v. 79, p. 488-506, 2006. 
KORAD, C. P.; BOOTH, D. B. Hydrologic changes in urban streams and their ecological significance. American Fisheries Society Symposium, v. 47, p. 157-177, 2005.

NARDY, A. J. R. Geologia e petrologia do vulcanismo mesozoico da Região Central da Bacia do Paraná. Tese de Doutorado. Rio Claro: IGCE-UNESP, 1995.

NASCIMENTO, E.; VIEIRA, E.; DEIMLING, C. D. Mapeamento da evolução da área urbanizada no município de Chapecó/SC. In: XVII Encontro Nacional de Geógrafos. Belo Horizonte: Associação dos Geógrafos Brasileiros, 2012.

NIMER, E. Climatologia do Brasil. 2. ed. Rio de Janeiro: IBGE, Depto. de Recursos Naturais e Estudos Ambientais, 1989.

Mapoteca Topográfica Digital de Santa Catarina. Epagri/IBGE, 2004.

MENDONÇA, F. A.; DANNI-OLIVEIRA, I. M. Climatologia: noções básicas e climas do Brasil. São Paulo: Oficina de Textos, 2007.

OLIVEIRA, E. D.; VESTENA, L. R. Alterações na morfologia de canais fluviais na área urbana de Guarapuava (PR). Ambiência, v. 8, ed. especial I, p. 757-773, 2012.

PARK, C. C. Channel cross-sectional change. In: GURNELL, A. E.; PETTS, G. Changing river channels. Ed. Wiley, 1995, p.117-145.

PELUSO JÚNIOR, V. A. O relevo do território catarinense. Geosul, n. 2, p. 7-69, 1986.

PREFEITURA MUNICIPAL DE CHAPECÓ. Chapecó em dados (agosto 2011). Disponível em: <http://www.chapeco.sc.gov.br/chapeco/chapeco-dados. html>. Acesso em: 15 dez. 2011.

SCHEIBE, L. F. A geologia de Santa Catarina: sinopse provisória. Geosul, n. 1, p. 7-38, 1986.

SOARES FILHO, A.; COMUNELLO, E.; RIBEIRO, A. F. N. Geotecnologias na caracterização espaço-temporal do uso do solo em bacias hidrográficas. In: SILVA, C. A. (Org.). Geografia e natureza: experiências e abordagens de pesquisas. Dourados: UFGD, 2012. p. 227-256.

TUCCI, C. E. M. Águas urbanas. In: TUCCI, C. E. M.; BERTONI, J. C. (Org.). Inundações urbanas na América do Sul. Porto Alegre: Associação Brasileira de Recursos Hídricos, 2003a. p. 11-44.

TUCCI, C. E. M. Inundações e drenagem urbana. In: TUCCI, C. E. M.; BERTONI, J. C. (Org.). Inundações urbanas na América do Sul. Porto Alegre: Associação Brasileira de Recursos Hídricos, 2003b. p. 45-141.

VIEIRA, V. T.; CUNHA, S. B. Mudanças na rede de drenagem urbana de Teresópolis-RJ. In: GUERRA, A. J. T.; CUNHA, S. B. (Orgs.). Impactos ambientais urbanos no Brasil. 4. ed. Rio de Janeiro: Bertrand Brasil, 2006. p. 111-145.

ZENI, V. L. F. ; JACOSKI, C. A. Diagnóstico socioambiental a partir do cadastro técnico ambiental da microbacia hidrográfica do Rio Passo dos Índios, Chapecó-SC. In: XI Encuentro de Geógrafos de América Latina. Bogotá: Universidad Nacional de Colômbia, 2007.

\section{Correspondência:}

André Luís Binda - Universidade Federal da Fronteira Sul. - Rua Gneral Osório, 413D. Bairro Jardim Itália, Chapecó - SC, CEP 89802-210.

E-mail: abinda@uffs.edu.br

Recebido em 13 de março de 2013.

Geografia Ensino \& Pesquisa, v. 17, n. 2 p. 243-259, maio/ago. 2013

Revisado pelo autor em 12 de abril de 2013.

Binda, A. L; Fritzen, M. 